\title{
Perda de solo na bacia do rio São Lamberto com uso de séries temporais de imagens Landsat
}

\section{Soil loss in the São Lamberto river basin with use of temporary series of Landsat images}

\author{
Alan Hakinen Aquino Tolentino \\ Universidade Federal de Minas Gerais \\ E-mail: alanhakinen@hotmail.com \\ OrcID: https://orcid.org/0000-0002-5066-4898 \\ Edson de Oliveira Vieira \\ Universidade Federal de Minas Gerais \\ E-mail: eovieira@ica.ufmg.br \\ OrclD: https://orcid.org/0000-0001-8738-5369 \\ Bruna Nogueira Rezende \\ Universidade Federal de Minas Gerais \\ E-mail: bruna.n.rezende@unesp.br \\ OrcID: https://orcid.org/0000-0003-4337-9324 \\ Pedro Augusto Alves Amaral \\ Universidade Federal de Minas Gerais \\ E-mail: pedroaugustoalves@hotmail.com \\ OrcID: https://orcid.org/0000-0002-0980-1432 \\ Leidivan Almeida Frazão \\ Universidade Federal de Minas Gerais \\ E-mail: leidivan.ufmg@gmail.com \\ OrcID: https://orcid.org/0000-0001-6848-9007
}

Resumo: O rio São Lamberto é um importante afluente do rio Jequitaí na bacia do Rio São Francisco e é fonte de água para projetos de irrigação e, principalmente, pecuária na região, e são poucos os estudos de análise de superfície de sua bacia submetido ao uso e ocupação do solo ao longo dos anos. O objetivo do trabalho foi estimar a perda de solo no contexto da evolução dos usos e ocupação do solo na Bacia do rio São Lamberto, MG, por meio do uso de dados orbitais e séries temporais de imagens LANDSAT associadas à aplicação da Universal Soil Loss Equation - USLE. Foram elaborados um vetor de delimitação da bacia através do software ArcGIS $10.1 \mathrm{com}$ aquisição de imagens LANDSAT 5-TM e LANDSAT 8-OLI, e classificação supervisionada destas. Foram obtidos os fatores da USLE para elaboração do mapa de susceptibilidade à perda de solo (fator A) nos anos 1995, 2005 e 2015. A partir da utilização do módulo LEGAL do SPRING 5.2 gerou-se os mapas de susceptibilidade a perda de solos, para os três anos estudados. As classes utilizadas foram: vegetação densa (cerradão), cerrado, pastagem, pasto sujo, área agrícola, área urbana e solo exposto. Verificou-se que a classe vegetação densa se mostrou predominante ao longo dos anos de 1995, 2005 e 2015, com 47,55\%, 41,13\% e $38,84 \%$, respectivamente, da área total da bacia. Conclui-se a que a Bacia do rio São Lamberto, demostrou boa conservação de sua cobertura do solo com $91,2 \%$ de suas áreas apresentando baixa susceptibilidade à ocorrência de erosão laminar (0 a 10 t.ha ${ }^{-1} \cdot a^{-1}$ ). 
Palavras-chave: Equação Universal de Perda de Solos, erosividade, erodibilidade, SIG

\begin{abstract}
The São Lamberto river is an important tributary of the Jequitaí river in the São Francisco river basin. This river is a source of water for several activities as irrigation and, mainly, livestock in the region and almost no study has been done to analyze the surface of its basin submitted to the use and occupation of the soil over the years. The objective of this work was to estimate soil loss in the context of environmental degradation in the São Lamberto River basin, MG, using orbital data and time series of LANDSAT images associated to the application of the Universal Soil Loss Equation-USLE. The procedures to perform the work included the elaboration of the basin delimitation vector using ArcGIS 10.1 software, LANDSAT 5-TM and LANDSAT 8-OLI image acquisition, and supervised classification of these. The factors $R, K$, LS and CP were obtained for the preparation of the soil loss susceptibility map (factor A) in the years 1995, 2005 and 2015. Using the LEGAL module of SPRING 5.2, the maps of susceptibility to soil loss, for the three years studied. It was verified from the elaborated maps that the dense vegetation class was predominant throughout the years of 1995, 2005 and 2015 , with $47.55 \%, 41.13 \%$ and $38.84 \%$, respectively, of the total area of the basin. It is concluded that the São Lamberto River Basin, showed good land cover conservation, with $91.2 \%$ of its areas presenting low susceptibility to the occurrence of laminar erosion ( 0 to 10 ton.ha- $^{-1}$.year ${ }^{-1}$ ).
\end{abstract}

Keywords: Universal Soil Loss Equation, Erosivity, Erodibility, GIS

Data de recebimento: $30 / 04 / 2018$

Data de aprovação: 16/04/2020

DOI: https://doi.org/10.30612/agrarian.v13i49.8013

\title{
Introdução
}

Os processos erosivos do solo evoluem de forma rápida e geram grandes desequilíbrios ambientais e econômicos. A degradação do solo ocorre principalmente pelo processo de desagregação e carreamento de partículas ricas em nutrientes, contribuindo para a redução da fertilidade e inutilização de áreas agricultáveis. Além disto, os sedimentos transportados promovem assoreamento e poluição em redes hidrográficas, reduzindo a seção de vazão dos leitos dos rios. A perda de solo por erosão hídrica diminui a espessura do solo e, consequentemente, a capacidade de retenção de água, aumentando o escoamento superficial (Santos; Griebeler \& Oliveira, 2010).

Vale Júnior et al. (2009) afirmam que a perda de solo por erosão provoca a redução dos rendimentos das culturas, amplia os custos de produção, diminuindo, portanto, a rentabilidade da lavoura. Todos estes fatores fazem com que a perda de solo seja um assunto de grande preocupação para produtores rurais e comunidade científica correlata, sendo um dos maiores problemas ambientais no que tange a conservação do solo tanto para a agricultura quanto para a manutenção dos ecossistemas locais. A ausência de práticas conservacionistas no uso e manejo do solo, comprometem a qualidade de vida do homem, bem como alteram as condições naturais dos mananciais, do solo, da flora e da fauna (Pereira; Sousa \& Campos, 2002).

A utilização de modelos prognósticos de perdas de solo por erosão e deposição de sedimentos pelo uso agrícola, como a Universal Soil Loss Equation (USLE), desenvolvida por Wischmeier e Smith (1978), é uma ferramenta utilizada para estimar a degradação do solo via erosão, avaliando qualitativamente as áreas de distintos graus de susceptibilidade à erosão, seja em estudos aplicados a bacias hidrográficas ou em solos experimentais (Silva \& Luchiari, 2016). Além da USLE, utilizam-se as geotecnologias como ferramentas importantes, representadas principalmente pelo Sensoriamento Remoto e pelo Sistema de Informações Geográficas (SIG). Assim, os estudos dos mecanismos de degradação do solo via erosão são de grande importância no diagnóstico dos fatores com maior potencial erosivo, podendo ser estimados mediante a utilização da USLE e aplicações de geoprocessamento.

Devido a intensificação da realização de práticas antrópicas na bacia do rio São Lamberto, com o crescimento de áreas irrigadas e principalmente da implementação de pastos para a pecuária torna-se necessário o constante monitoramento das perdas de solo inerentes a estes processos. O rio São Lamberto é 
um importante afluente do rio Jequitaí, MG, e possui uma complexa relação entre os sistemas água-solovegetação, sendo considerada uma bacia de grande vulnerabilidade. O conhecimento das áreas de susceptibilidade às perdas de solo nessa bacia hidrográfica permitirá a adoção de práticas conservacionistas a serem desenvolvidas pontualmente nas áreas afetadas, garantindo a inter-relação entre os elementos bióticos e abióticos, produção e sustentabilidade.

Nesse sentido, o objetivo do presente estudo foi estimar a perda de solo na Bacia do rio São Lamberto/MG, nos anos de 1995, 2005 e 2015, por meio do uso de dados orbitais e séries temporais de imagens LANDSAT-5/TM e LANDSAT-8/OLI associadas à aplicação da Equação Universal de Perda de Solo (USLE).

\section{Material e Métodos}

\section{Área de estudo}

A Bacia do rio São Lamberto, MG, é uma das sub-bacias do rio São Francisco e seu curso principal corresponde a um afluente da margem direita do rio Jequitaí. Localiza-se na região Norte do estado de Minas Gerais e abrange os municípios de Montes Claros, Claro dos Poções e Jequitaí em quase toda a sua extensão (Figura 1). Pequenas regiões da bacia compreendem ainda os municípios de São João da Lagoa, Francisco Dumont e Bocaiuva, onde neste último encontra-se a nascente do rio São Lamberto. A área total da bacia é de aproximadamente 120.200 ha.

De acordo com a classificação de Köpen, o clima da região é do tipo Aw, caracterizado por clima tropical e período de inverno seco. A precipitação anual varia de $750 \mathrm{~mm}$ a $1800 \mathrm{~mm}$ e as temperaturas. Este tipo de clima é predominante em praticamente todo norte de Minas Gerais (Antunes, 1986). Em relação à vegetação, o bioma cerrado apresenta grande predominância nas bacias dos rios São Francisco e Jequitinhonha, com vegetação composta por gramíneas, arbustos e árvores.

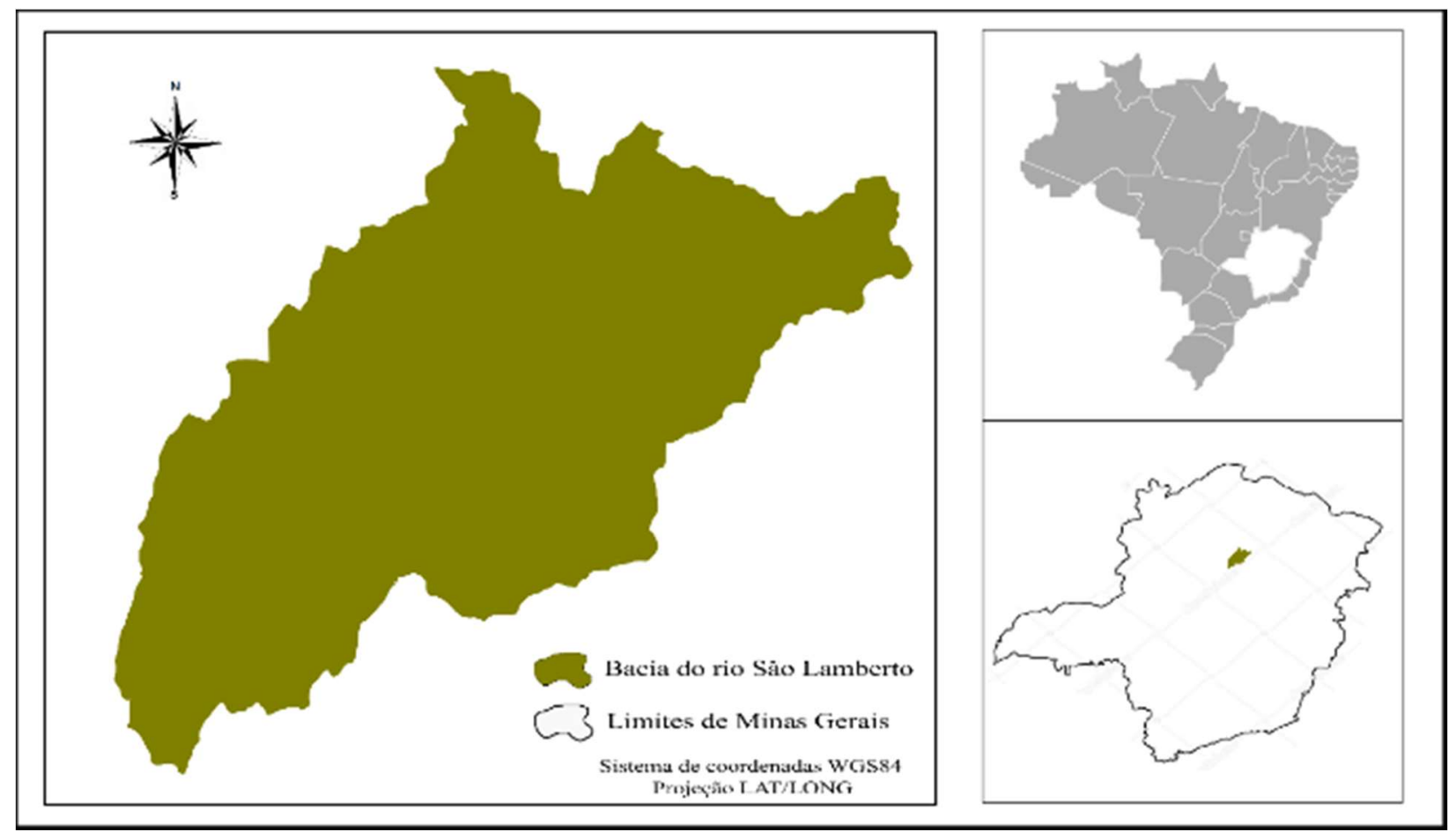

Figura 1. Localização espacial da Bacia do rio São Lamberto no estado de Minas Gerais. 


\section{Definição dos parâmetros da USLE para os anos de 1995, 2005 e 2015}

O modelo utilizado para quantificar a perda de solo por erosão laminar para a Bacia do rio São Lamberto, foi a USLE (Eq. 1), proposta por Wischmeier e Smith (1978). Este modelo calcula a perda média de solo devido à erosão laminar e por sulcos, para longos períodos, e sua aplicação visa a orientação sistemática no planejamento da conservação do solo (Paiva, 2001).

$$
A=R \times K \times L \times S \times C \times P
$$

Onde: A - Perda de solo calculada, em t.ha- $a^{-1}$ ano $^{-1} ; \mathrm{R}$ - Fator chuva, em MJ.mm ha- ${ }^{-1} \cdot \mathrm{h}^{-1} \cdot \mathrm{ano}^{-1} ; \mathrm{K}$ - Fator de erodibilidade do solo em t.ha. $\mathrm{MJ}^{-1} \cdot \mathrm{mm}^{-1} ; \mathrm{L}$ - Comprimento do declive em $\mathrm{m} ; \mathrm{S}$ - Fator grau de declive em \%; $C$ - Fator de uso e manejo $(0-1) ; P$ - Fator de práticas conservacionistas $(0-1)$.

\section{Fator de erosividade da chuva - $\mathbf{R}$}

O fator de erosividade $(R)$ foi obtido por meio do software NetErosividade MG (Moreira et al., 2008), sendo adquirido um valor para cada município integrante da sub-bacia hidrográfica do rio São Lamberto (Tabela 1).

Tabela 1. Fator $R$ para os municípios integrantes da Bacia do rio São Lamberto, MG

\begin{tabular}{cc}
\hline Município & $\mathbf{R}\left(\mathrm{MJ} \cdot \mathrm{mm} \mathrm{ha}^{-1} \cdot \mathrm{h}^{-1} \cdot \mathrm{ano}^{-1}\right)$ \\
\hline Bocaiuva & 3556 \\
Claro dos Poções & 3578 \\
Francisco Dumont & 3843 \\
Jequitaí & 3172 \\
Montes Claros & 2156 \\
São João da Lagoa & 3909 \\
\hline
\end{tabular}

Fonte: Software NetErosividade (2008).

Tabela 2. Valores de K para as classes de solo da Bacia do rio São Lamberto, MG

\begin{tabular}{ccc}
\hline Classe de solo & K (t.ha.M J-1. $\mathbf{m m}^{-1}$ ) & Fonte \\
\hline Cambissolo Háplico & 0,0254 & Mannigel et al., 2002 \\
Latossolo Vermelho Amarelo & 0,0112 & Mannigel et al., 2002 \\
Neossolo Litólico & 0,0368 & Reatto et al., 2000 \\
\hline
\end{tabular}

O mapa de erosividade foi gerado através da aplicação dos valores tabelados acima em um algoritmo de ponderação, desenvolvido através da operação de álgebra de mapas do módulo LEGAL (Linguagem Espacial para Geoprocessamento Algébrico) do SPRING 5.2.2, que transforma imagens temáticas em imagens numéricas. Para a obtenção do fator erosividade, foram considerados os diferentes municípios integrantes da Bacia do rio São Lamberto, atribuindo um valor específico para cada unidade. Estes valores foram adquiridos por meio do software NetErosividade MG (Moreira et al., 2008), e foram utilizados para todos os períodos analisados, uma vez que se considera a média histórica de precipitação.

Fator erodibilidade dos solos - K 
A susceptibilidade à ocorrência de erosão (fator $\mathrm{K}$ ) é determinada pelo tipo de solo. Esta informação foi fornecida pela Empresa Brasileira de Pesquisa Agropecuária - EMBRAPA, de acordo com o novo Sistema Brasileiro de Classificação de Solos (Santos et al., 2018), e foi disponibilizado em formato shapefile pelo Instituto Brasileiro de Geografia e Estatística (IBGE, 2001). Foi realizado o recorte do vetor tipo de solo para representação apenas da área da bacia. $\mathrm{O}$ fator $\mathrm{K}$ (Tabela 2) foi obtido a partir da ponderação de valores correspondentes a cada classe de solo de ocorrência na bacia, por meio da operação de álgebra de mapas do módulo LEGAL do software Spring 5.2.2.

\section{Fator topográfico - LS}

O fator topográfico (LS) é a avaliação conjunta das variáveis comprimento de rampa (L) e declividade $(S)$, que influenciam na perda do solo oriunda da erosão laminar em bacias hidrográficas. A metodologia de referência foi elaborada por Bertoni e Lombardi Neto (2010), conforme equação 2:

$$
\text { LS }=0,00984 \times \gamma^{0,63} \times D^{1,18}
$$

Onde: $\gamma=$ Comprimento da rampa médio em metros; $\mathrm{D}=$ Declividade em porcentagem.

A metodologia proposta por Villela e Mattos (1975) foi aplicada para obtenção do comprimento de rampa médio (Eq. 3):

$$
\gamma=\mathrm{A} / 4 \mathrm{I}
$$

Onde: $\gamma$ = Comprimento de rampa médio; $\mathrm{A}=$ Área da bacia $\left(\mathrm{m}^{2}\right) ; \mathrm{I}$ = Somatório do comprimento de todos os cursos d'água da bacia $(\mathrm{m})$.

As imagens SRTM $16 S 45$ e $17 S 45$ de declividade foram obtidas junto ao Projeto TOPODATA. O mosaico das imagens foi criado a fim de uni-las em uma única imagem. Posteriormente, a imagem foi recortada a partir do vetor de delimitação da bacia e convertida no formato MNT do SPRING (Modelo Numérico do Terreno) para geração de uma grade de pontos que possibilita a realização das operações de álgebra de mapas no módulo LEGAL. Elaborou-se um algoritmo de ponderação para a geração do mapa LS a partir da aplicação das equações citadas à imagem de declividade. Utilizando os intervalos de classificação elaborados por Minoti (2006), adotou-se os seguintes valores para a definição das classes: 0 a 1 (muito baixo); 1 a 5 (baixo); 5 a 10 (moderado); 10 a 50 (alto); e acima de 50 (muito alto). A declividade para a bacia em $\mathrm{cm} . \mathrm{m}^{-1}$, foi classificada de acordo com o proposto por Embrapa (1999): 0-3 (plano); 3-8 (suave ondulado); 8-20 (ondulado); 20-45 (forte ondulado); 45-75 (montanhoso), e 75-100 (escarpado).

\section{Fator CP - Variável antrópica}

O fator C representa o grau de proteção contra os impactos dos processos erosivos em decorrência do tipo de cobertura do solo e técnicas de manejo existentes. O fator $\mathrm{P}$ corresponde à intensidade da perda de solo resultante da utilização de práticas conservacionistas de caráter mecânico. Os fatores $C$ e $P$ foram analisados de forma integrada em função do uso e ocupação do solo. Atribuiu-se o valor 1 (um) para o fator $P$, considerando dessa forma a ausência de práticas conservacionistas na região. A variável antrópica CP foi definida para os anos de 1995, 2005 e 2015. O processo consistiu na atribuição dos valores de CP equivalentes a cada tipo de classe obtida no mapa de uso e ocupação do solo (Tabela 3). Dessa forma, os mapas temáticos de uso e ocupação do solo tiveram valores atribuídos a cada uma de suas classes através da utilização de um algoritmo de ponderação no ambiente LEGAL do SPRING. A imagem resultante no modelo numérico foi 
submetida ao processo de fatiamento de acordo com intervalos definidos, para a posterior geração do mapa de CP referente a cada ano.

Tabela 3. Integração de CP em função das classes de uso e ocupação do solo.

\begin{tabular}{ccc}
\hline Classe de uso do solo & CP & Fonte \\
\hline Mata densa & 0,00004 & Stein et al., 1987 \\
Cerrado & 0,0007 & Stein et al., 1987 \\
Pastagem & 0,12 & Stein et al., 1987 \\
Pasto sujo & 0,25 & Stein et al., 1987 \\
Área agrícola & 0,20 & Stein et al., 1987 \\
Solo exposto & 1,0 & Stein et al., 1987 \\
Área urbana & 0,1 & Tomazoni \& Guimarães, 2005 \\
\hline
\end{tabular}

Segundo Stein et al. (1987), quando se objetiva espacializar fenômenos por meio da utilização de geoprocessamento, a obtenção dos dados dos fatores C (uso e manejo) e P (prática conservacionista) pode ser realizada de forma integrada em função do uso e ocupação do solo. Neste caso, considerou-se a pior situação de perdas de solo em função de práticas conservacionistas $(P=1)$. Associou-se a cada classe existente no mapa de classificação de uso e ocupação do solo, um fator que varia de 0 a 1 , sendo o valor 1 a condição de ausência de aplicação de práticas conservacionistas. As áreas tiveram atribuição dos seguintes valores para o fator CP: mata densa, cerradão $=0,00004$; cerrado $=0,0007$; pastagem $=0,12$; pasto sujo $=$ 0,25 ; solo exposto $=1,00$; área agrícola $=0,20$.

Para a elaboração dos mapas, realizou-se a aquisição das imagens do Instituto Nacional de Pesquisas Espaciais (INPE) a partir do satélite LANDSAT - 5, sensor TM. Obteve-se ainda junto ao United States Geological Survey (USGS) uma imagem LANDSAT-8 sensor OLI para o ano de 2015. As imagens localizamse na órbita/ponto 218/72 e foram adquiridas para o mês de julho dos anos de 1995, 2005 e 2015, período em que há ausência de nuvens por se tratar de uma estação seca do ano.

Foram utilizados dados SRTM (Shuttle Radar Topography Mission) de altimetria da região de estudo, processados através do Projeto TOPODATA, de resolução espacial de 90 m e elipsóide de referência WGS84. As imagens foram importadas no software ArcGIS versão 10.1 software ${ }^{\circledR}$ ESRI, com criação de mosaico das imagens SRTM 16S45 e 17S45 para posterior utilização desta no procedimento de delimitação automática da bacia hidrográfica, através do uso das extensões "Spatial Analyst Tools" e "Hydrology". Foi utilizado um ponto shapefile de coordenadas referentes à foz do rio São Lamberto para delimitação da bacia ("Hydrology > Watershed").

O processamento de imagens foi realizado no ENVI 4.2 software ${ }^{\circledR}$ ESRI e incluiu o georreferenciamento da GeoCover (Global Land Cover Facility), imagens fornecidas pela NASA (National Aeronautics and Space Administração). O método utilizado foi a seleção de 30 pontos de controle da imagem GeoCover e os mesmos pontos na imagem LANDSAT-5 / TM para georreferenciamento. Após esta etapa, foi realizado o recorte das imagens a partir do arquivo vetorial de delimitação da bacia utilizando o software SPRING 5.2.2. As imagens foram padronizadas para a projeção UTM e datum WGS-84. Utilizou-se a composição colorida de falsa cor RGB-453 para melhor distinção de classes, para o tipo de classificação "pixel a pixel", que analisam a informação espectral de cada pixel para detectar regiões homogêneas.

O algoritmo classificador escolhido foi o MAXVER (Máxima Verossimilhança), do tipo supervisionado devido à necessidade da definição de amostras de classes para geração de estatística. Foi escolhido o limiar de aceitação de $100 \%$ por apresentar classificação mais adequada, discriminando satisfatoriamente as classes definidas. As classes de ocupação existentes na área foram identificadas através de informações obtidas em campo. Em virtude da vegetação que representa a proteção do solo, foram definidas sete classes: vegetação densa (cerradão), cerrado, pastagem, pasto sujo, área agrícola, área urbana e solo exposto.

\section{Resultados e Discussão}

Agrarian, Dourados, v. 13, n. 49, p. 362-376, 2020. 


\section{Uso e ocupação do solo na bacia}

A partir da classificação de imagens LANDSAT 5-TM para a área delimitada da Bacia do rio São Lamberto, MG, foram gerados mapas temáticos que representaram as atividades de uso e ocupação do solo na bacia para os períodos de 1995, 2005 e 2015. A Tabela 4 mostra o percentual de áreas referentes a cada classe de uso e ocupação para os anos analisados. O índice Kappa para essa classificação foi de 0,89.

O ano de 1995 apresentou maior ocorrência de áreas de vegetação densa com tipo de cobertura total do terreno. Esta vegetação, no entanto, mesmo ainda se mantendo predominante ao longo dos anos do estudo, sofreu consideráveis reduções ao longo dos anos, traduzidas na diminuição de quase 10.500 ha de suas áreas entre 1995 e 2015. Entre 2000 e 2010, a área global de floresta primária reduziu mais de 400.000 quilômetros quadrados. Em virtude da conversão de florestas em terras agrícolas, o desmatamento tem diminuído em vários países tropicais, mas segue em ritmo acelerado (Brasil, 2010).

Entre 1995 e 2015 houve diminuição da área do Cerrado de mais de 2.400 ha (2,04\%), correspondendo no ano de 2015 a 7,55\% da cobertura de solo da bacia (9.074,88 ha). Coutinho (1997) em seu trabalho de mapeamento do uso de terras na região de Campinas, SP, associa a redução dessas áreas à falta de manejo e abandono de atividades causadoras de alterações da vegetação, como o uso de terras para criação extensiva de gado, levando ao surgimento de áreas caracterizadas como pasto sujo. Percebeu-se a expansão dessas áreas, destacando-se a realização de práticas agrícolas, como a pecuária e carvoejamento, em algumas regiões integrantes da área da bacia.

Tabela 4. Percentual das classes de uso e cobertura do solo na Bacia do rio São Lamberto, MG para os anos de 1995, 2005 e 2015

\begin{tabular}{ccccccc}
\hline Classes de uso do solo & \multicolumn{2}{c}{$\mathbf{1 9 9 5}$} & \multicolumn{2}{c}{$\mathbf{2 0 0 5}$} & \multicolumn{2}{c}{$\mathbf{2 0 1 5}$} \\
\cline { 2 - 7 } & $\mathbf{( h a )}$ & $\mathbf{( \% )}$ & $\mathbf{( h a )}$ & $\mathbf{( \% )}$ & $\mathbf{( h a )}$ & $\mathbf{( \% )}$ \\
\hline Vegetação densa natural densa & $57.143,25$ & 47,55 & $49.423,95$ & 41,13 & $46.672,47$ & 38,84 \\
Pastagem & $34.513,47$ & 28,72 & $32.453,30$ & 27,01 & $31.490,73$ & 26,21 \\
Pasto sujo & $15.193,44$ & 12,64 & $22.979,13$ & 19,12 & $25.926,51$ & 21,58 \\
Cerrado & $11.520,27$ & 9,59 & $8.418,22$ & 7,01 & $9.074,88$ & 7,55 \\
Solo exposto & $1.640,43$ & 1,37 & $5.906,18$ & 4,91 & 5945,76 & 4,95 \\
Área agrícola & 93,15 & 0,08 & 906,12 & 0,75 & 969,64 & 0,81 \\
Área urbana & 64,80 & 0,05 & 81,7 & 0,07 & 88,61 & 0,07 \\
Total & $\mathbf{1 2 0 . 1 6 8 , 8 0}$ & $\mathbf{1 0 0 , 0 0}$ & $\mathbf{1 2 0 . 1 6 8 , 8 1}$ & $\mathbf{1 0 0 , 0 0}$ & $\mathbf{1 2 0 . 1 6 8 , 8}$ & $\mathbf{1 0 0 , 0 0}$ \\
\hline
\end{tabular}

As pastagens apresentaram pequenas diminuições do percentual de ocorrência ao longo dos anos, com redução total de $2,51 \%$ de suas áreas entre o período de 1995 e 2015. Uma das justificativas para essa pequena variação, se deve ao fato de que as áreas de pastagens já se encontravam implantadas, antes do período inicial estudado e se mantiveram praticamente inalteradas ao longo dos anos analisados. Porém, analisando conjuntamente pastagens e pasto sujo, houve aumento de $6,43 \%$.

A classe de solo exposto corresponde às regiões mais degradadas encontradas. Estas regiões representavam no ano de 1995 aproximadamente 1.640 ha $(1,37 \%)$. Até o ano de 2005 houve grande incremento dessas áreas, evoluindo para 5.906,18 ha (4,91\%). No entanto, de 2005 em diante os fatores degradadores causadores desse grande aumento do número de áreas sem cobertura não promoveram a expansão das mesmas, de forma a se manter praticamente invariável ao longo dos nove anos posteriores a 2005, com 5.945,76 ha de área total em 2015.

Verifica-se que as áreas de solo exposto apresentam ocorrência mais acentuada em regiões de maiores altimetrias, com expansão dessas áreas no seu entorno e pelo surgimento de ocorrências pontuais distribuídas ao longo da área da bacia, influenciadas principalmente por processos antrópicos de pequena magnitude se analisados separadamente. De acordo com Araújo et al. (2009), a introdução moderna da agricultura causa 
impactos ambientais principalmente no Cerrado, por apresentar relevo propício a mecanização agrícola. As ações antrópicas potencializam as transformações que ocorrem na dinâmica da paisagem, afetando as bacias hidrográficas.

As áreas da bacia ocupadas com agricultura no ano de 1995 correspondiam a menos de 100 ha $(0,08 \%)$, referindo-se ao tipo de agricultura familiar de subsistência. Em 2005 houve a expansão dessas áreas, se dando principalmente em regiões de mata densa e pastagem. No ano de 1995, a bacia apresentou baixa interferência antrópica associada à degradação da cobertura vegetal, apresentando-se de forma geral bem vegetada (Figura 2).

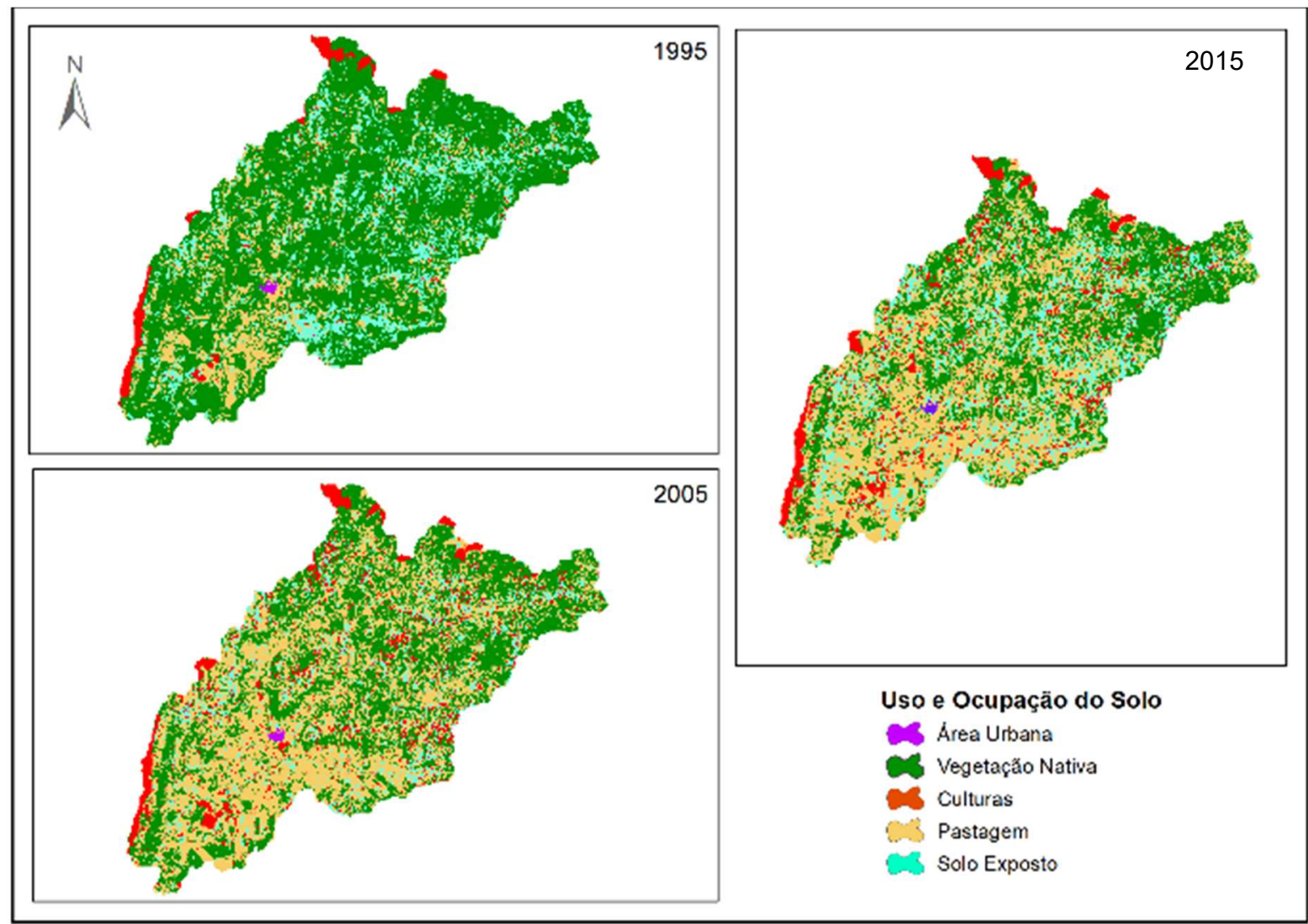

Figura 2. Uso e ocupação do solo na Bacia do rio São Lamberto, MG, para os anos de 1995, 2005 e 2015.

Conforme apresentado na Figura 2, em 2005 além do aumento das áreas de solo exposto, tonou-se mais evidente a diminuição das áreas vegetadas, principalmente em relação às regiões de mata densa (cerradão).

A análise do uso do solo para o ano de 2015 (Figura 2), mostra a contínua redução da mata nativa em comparação aos períodos anteriores e o aumento das áreas de pasto sujo e solo exposto, demostrando a influência dos processos antrópicos na caracterização da região. As variações das classes de uso e ocupação do solo ao longo dos períodos de estudo podem ser visualizadas na Figura 3. Redivo et al. (2003), estudando o uso do solo no trecho do rio São Francisco no período de 1950 e 1999, relataram que a vegetação primária foi reduzida a $11 \%$ da área total em 1999. Esta redução é explicada pela expansão agrícola na região. As áreas com solo exposto passaram de $2 \%$ em 1950 para $22 \%$ em 1999. No entanto, o maior crescimento refere-se às áreas com modificação antrópica. 


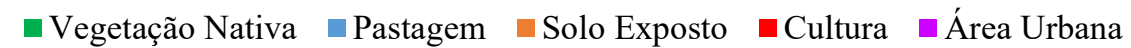

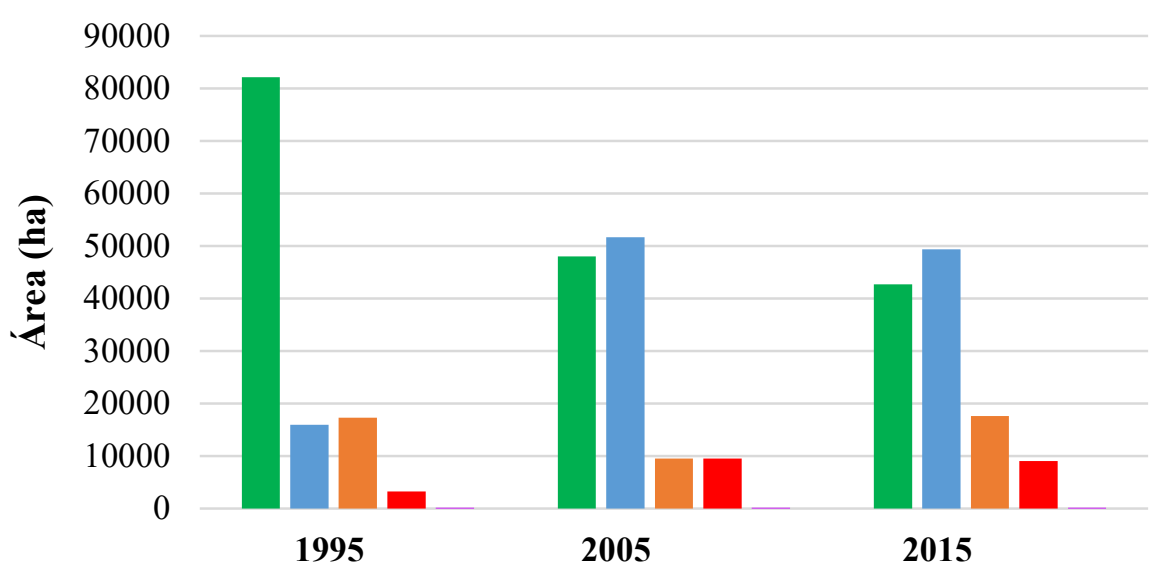

Figura 3. Dinâmica das áreas de uso e ocupação do solo na Bacia do rio São Lamberto, MG.

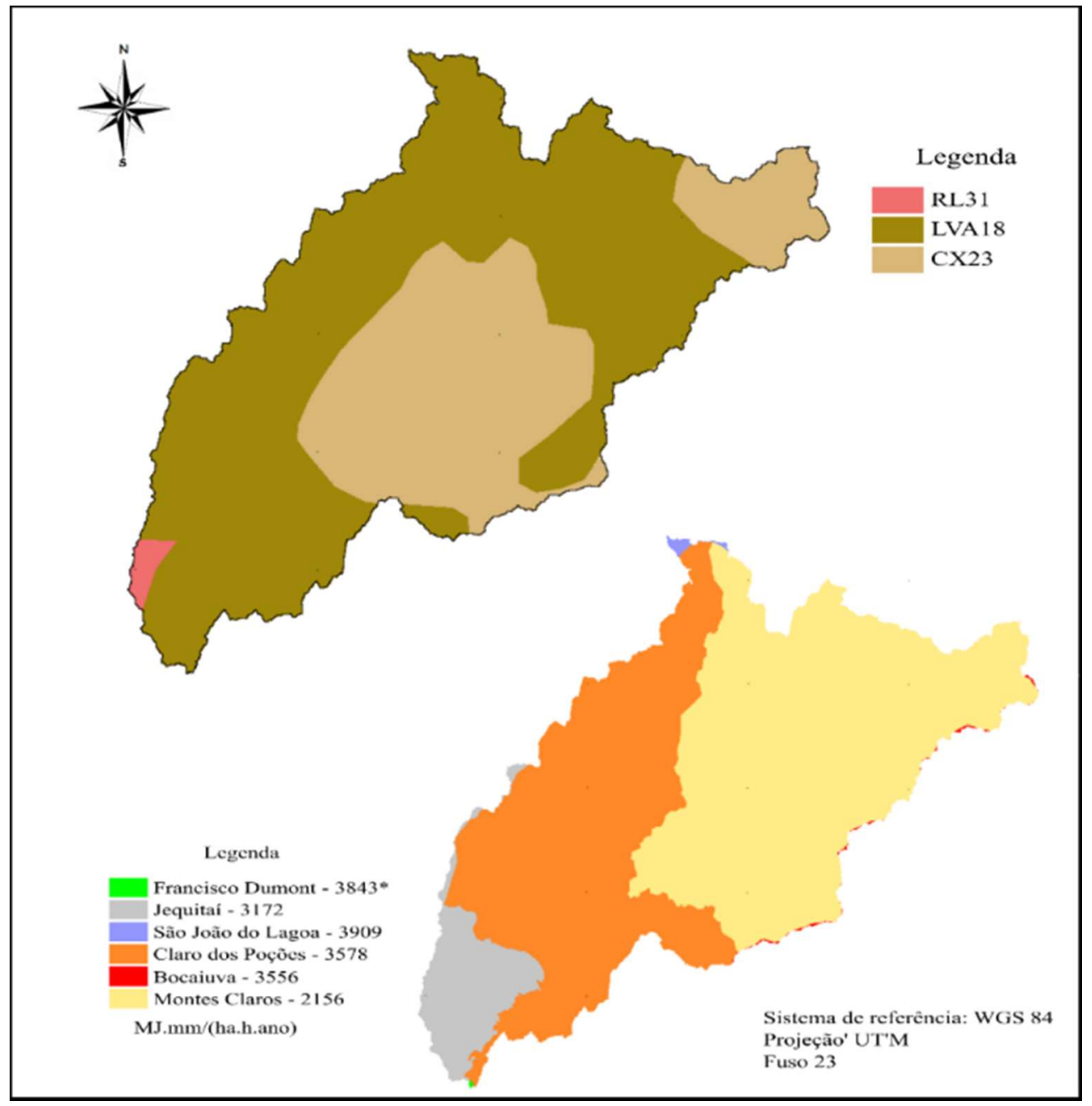

Figura 4. Localização das classes de solos Neossolo Litólico (RL), Latossolo Vermelho-Amarelo (LVA), Cambissolo Haplico (CX) e do fator R na Bacia do rio São Lamberto, MG.

Agrarian, Dourados, v. 13, n. 49, p. 362-376, 2020. 


\section{Fatores de erodibilidade da bacia}

Apesar da abrangência territorial de seis municípios do norte de Minas Gerais: Montes Claros, Claro dos Poções, Jequitaí, São João da Lagoa, Bocaiuva e Francisco Dumont, apenas os três primeiros somados representam $99,6 \%$ da área total (Figura 4). A variação do fator $R$ para estes municípios foi de $2.156 \mathrm{MJ} . \mathrm{mm}$ $\mathrm{ha}^{-1} \cdot \mathrm{h}^{-1} \cdot \mathrm{ano}^{-1}$ a $3.578 \mathrm{MJ} \cdot \mathrm{mm} \mathrm{ha} \mathrm{H}^{-1} \cdot \mathrm{h}^{-1} \cdot \mathrm{ano}^{-1}$.

Verificou-se que $99,2 \%$ das áreas da bacia compreendem regiões de baixa erodibilidade $(\mathrm{K}<0,03)$. A região com erodibilidade média $(0,03<\mathrm{K}<0,06)$ coincide com a ocorrência do solo Neossolo Litólico $(R L)$, na porção correspondente à $0,78 \%$ da área total. Os valores de $\mathrm{K}$ utilizados foram associados aos respectivos tipos de solo presentes ao longo da área da bacia e transformados em formato de grade (raster). Foster et al. (1981) classificaram a erodibilidade dos solos dos Estados Unidos da América nas seguintes classes: baixo para valores entre 0,01 e 0,03 t.h. $\mathrm{MJ}^{-1} \cdot \mathrm{mm}^{-1}$; médio para valores entre 0,03 e 0,06 t.h. $\mathrm{MJ}^{-1} \cdot \mathrm{mm}^{-1}$ e alto para valores acima de 0,06 t.h. $\mathrm{MJ}^{-1} \cdot \mathrm{mm}^{-1}$.

Portanto, a Bacia do rio São Lamberto, não possui áreas com alta erodibilidade, e apenas $0,8 \%$ desta possui erodibilidade média. Justifica-se esse resultado principalmente pela predominância de Latossolo Vermelho-Amarelo (LVA), em 64,9\% da área, e Cambissolo Haplico (CX), com 34,3\% de ocorrência (Figura 7).

De acordo com nomograma desenvolvido por Wischmeier et al. (1971), a erodibilidade em solos profundos, tais como os predominantes na bacia, é mais baixa que em solos mais rasos, com valores de 0,020 t.h. $\mathrm{MJ}^{-1} \cdot \mathrm{mm}^{-1}$ e 0,024 t.h. $\mathrm{MJ}^{-1} \cdot \mathrm{mm}^{-1}$, respectivamente para Latossolo Vermelho-Amarelo e Cambissolo Haplico (CX). Os Neossolos Litólicos são solos rasos, normalmente associados a relevos mais declivosos.

Em relação a declividade, há o predomínio do tipo de relevo ondulada, presente em $41,81 \%$ da extensão da bacia, seguido pelo relevo suave ondulado (26,32\%), forte ondulado (18,08\%), montanhoso $(0,86 \%)$ e escarpado $(0,32 \%)$. Verificou-se que a porção sul da bacia apresenta predomínio de relevo plano ao longo de uma área contínua, situação oposta à porção norte, onde há maior ocorrência de relevo ondulado a forte ondulado (Figura 5).

Na Figura 5 pode ser visualizada a influência do tipo de relevo na determinação do fator LS. A figura evidencia que os maiores valores de LS encontram-se relacionados às declividades mais altas, assim como as áreas mais planas da bacia, de menores declividades, que apresentam os menores valores de LS. Obteve-se na área da bacia a seguinte distribuição: $73,58 \%$ correspondente a LS muito baixo, $25,65 \%$ baixo, $0,75 \%$ moderado, $0,009 \%$ alto e $0,011 \%$ equivalente ao fator LS muito alto. Os valores de LS gerados foram utilizados para os três períodos analisados, pois o fator foi considerado invariável em relação ao curto intervalo de tempo, considerando-se o tempo geológico necessário para o acontecimento de mudanças significativas.

\section{Susceptibilidade a erosão laminar na bacia}

Apresentados os resultados obtidos através dos processamentos com utilização da álgebra de mapas, correspondentes aos fatores da USLE, tornou-se possível a avaliação da susceptibilidade à ocorrência de erosão na área de estudo (fator A), a partir da geração de mapas para os anos de 1995, 2005 e 2015 . A Food and Agriculture Organization (FAO) classificou os intervalos de predisposição do solo nas seguintes classes: perda baixa $\left(0-10\right.$ t.ha-1.ano $\left.{ }^{-1}\right)$; perda moderada $\left(10-50\right.$ t.ha ${ }^{-1}$.ano $\left.{ }^{-1}\right)$; perda alta $\left(50-200\right.$ t.ha ${ }^{-1}$.ano $\left.{ }^{-1}\right)$; e perda muito alta (> 200 t.ha $^{-1}$.ano-1) (FAO, 1967).

De acordo com a Tabela 5, notou-se o predomínio da classe referente a baixa perda de solos (0-10 t.ha ${ }^{1}$.ano-1 ${ }^{-1}$ durante todos os anos analisados, correspondendo a $94,82 \%, 92,49 \%$ e $91,20 \%$ da área, respectivamente para os anos 1995, 2005 e 2015. Estes dados demonstraram que mesmo sem adoção de práticas conservacionistas, a bacia apresentou variações de pequena magnitude em relação ao percentual de áreas de baixa susceptibilidade à perda de solo. 


\section{idigaraRIN \\ 1.
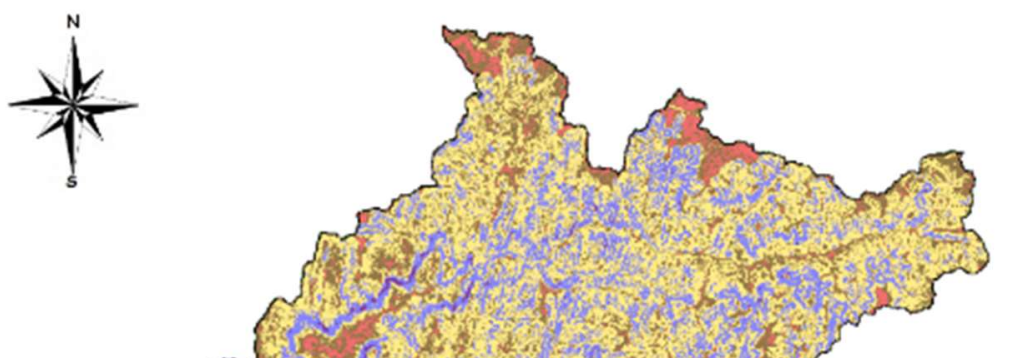

Legenda
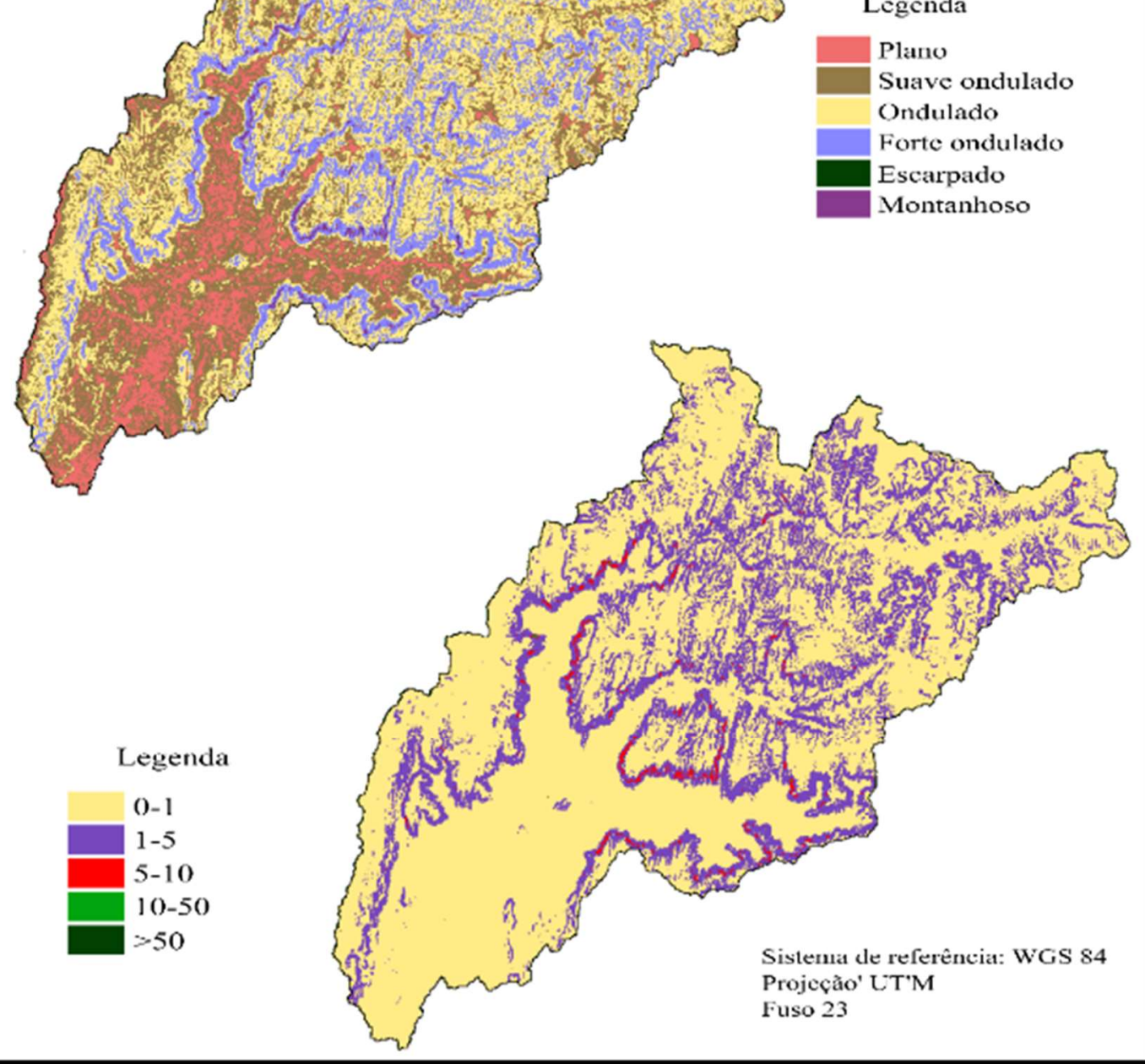

Figura 5. Tipos de relevo e fator LS da Bacia do rio São Lamberto, MG.

Tabela 5. Estimativa da perda de solo na Bacia do rio São Lamberto-MG, para os anos de 1995, 2005 e 2015.

\begin{tabular}{ccccc}
\hline Classes de perda de solo & $\mathbf{0 - 1 0}$ & $\mathbf{1 0 - 5 0}$ & $\mathbf{5 0 - 2 0 0}$ & $\mathbf{> 2 0 0}$ \\
\hline $\mathbf{1 9 9 5}$ (ha) & $113.938,55$ & $5.768,10$ & 413,73 & 48,42 \\
$\mathbf{2 0 0 5}$ (ha) & $111.116,15$ & $8.272,53$ & 638,01 & 95,94 \\
$\mathbf{2 0 1 5}$ (ha) & $109.594,28$ & $9.697,32$ & 767,88 & 109,32 \\
\hline
\end{tabular}

Portanto, tipos de solo, declividade e precipitação, fatores determinantes na obtenção dos fatores K, LS e $\mathrm{R}$, respectivamente, apresentaram-se favoráveis à menor susceptibilidade de ocorrência de processos erosivos, traduzidos por seus baixos valores para a área de estudo. Silva e Luchiari (2016), determinaram os

Agrarian, Dourados, v. 13, n. 49, p. 362-376, 2020. 
valores extremos médios anuais do fator $\mathrm{R}$ variando de 4.150 a $9.632 \mathrm{MJ} . \mathrm{mm} \mathrm{ha}^{-1} \cdot \mathrm{h}^{-1}$.ano-1. Comparando os valores obtidos na Tabela $1 \mathrm{com}$ a literatura, é possível identificar que a erosividade na bacia do rio São Lamberto é baixa.

Mais da metade da bacia ainda está preservada sem processo de antropização e a pequena variação que se verificou ao longo dos períodos analisados se deu pela dinâmica do uso e ocupação do solo, através do fator $\mathrm{CP}$, único fator variável ao longo do estudo. Este, por sua vez, mostrou-se em geral com predomínio de cobertura do solo favorável à conservação da bacia, traduzidas pela grande ocorrência de áreas bem vegetadas e menor percentual de áreas com princípios de degradação ou já degradadas, como as classes pasto sujo e solo exposto, embora apresentarem crescimento gradativo ao longo dos anos.

A Figuras 6 apresenta os mapas de predisposição à perda de solos na bacia, para os períodos de 1995, 2005 e 2015.

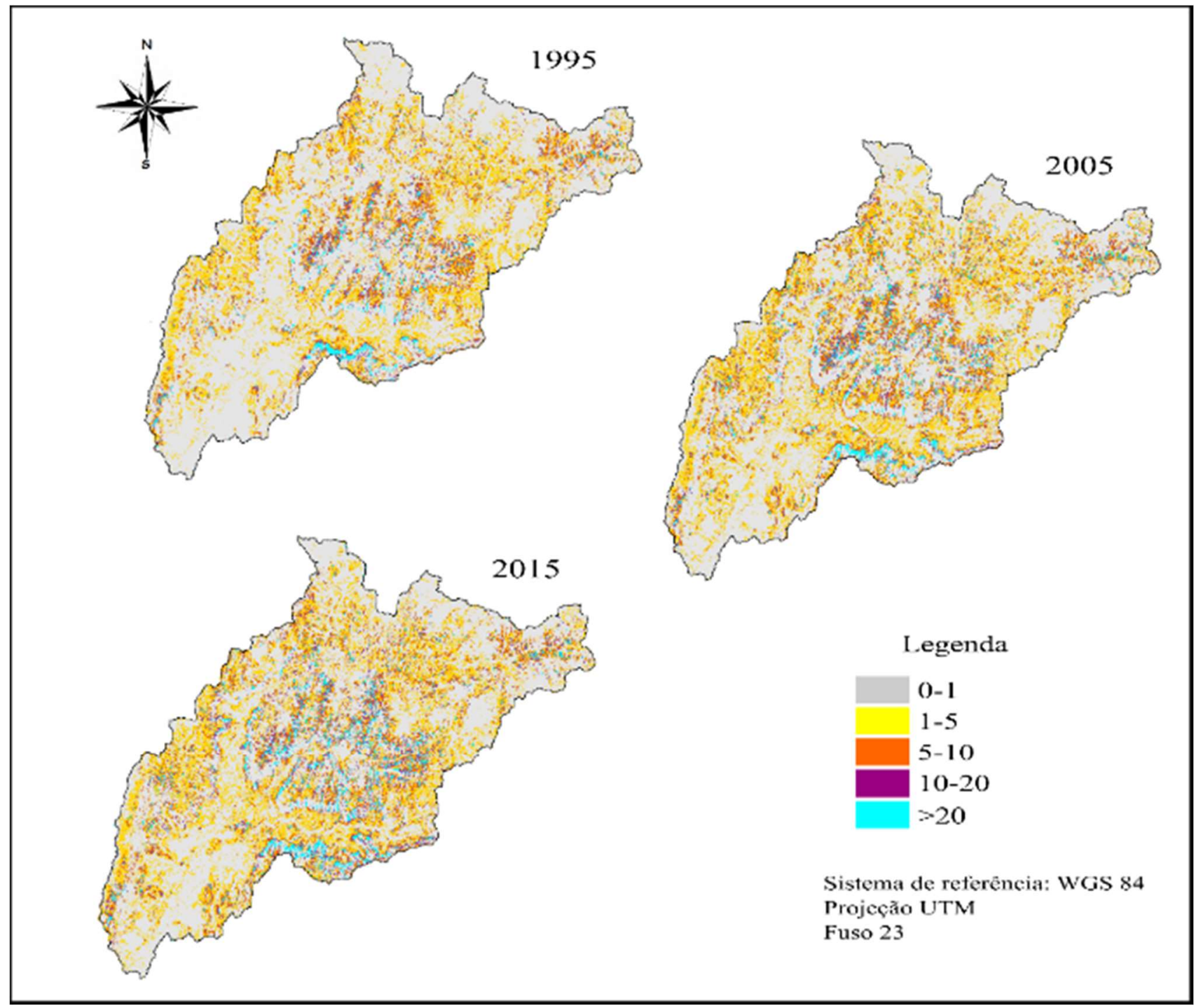

Figura 6. Mapa de perda de solo para os anos de 1995, 2005 e 2015 em t.ha-1.ano-1 da Bacia do rio São Lamberto, MG. 
Estes mapas foram elaborados utilizando intervalos de classificação mais adequados aos valores de perda de solo obtidos para a bacia, devido aos baixos valores apresentados. Logo, utilizou-se intervalos de 0 a 1 t.ha $^{-1}$.ano-1, 1 a 5 t.ha $^{-1}$. Silva e Luchiari (2016), avaliaram a estimativa de perda de solos por erosão na Bacia do Córrego Baguaçu, encontrando valores de 0 a 3 t.ha- $a^{-1}$.ano-1 com expectativa de erosão baixa. Áreas com maiores perdas de solos estão, na maioria, nas médias encostas de relevo de colinas médias e declividades maiores. Já Sousa e de Paula (2019), utilizando metodologias semelhantes a apresentada nesse trabalho para a bacia do rio Coreaú no Ceará, calcularam valores na ordem de 15,80 t.ha-1.ano-1 de solos a 50 t.ha $^{-1}$. ano $^{-1}$, sendo, nessas áreas, os processos erosivos são bem mais intensos.

\section{Conclusão}

A aplicação do SIG na caracterização e identificação da susceptibilidade a perdas de solo, estimadas através do modelo da USLE, se mostrou eficiente e de rápida aquisição de informações qualitativas;

A bacia do Rio São Lamberto, MG apresentou na série temporal analisada entre 1995 a 2015 apenas uma redução de sua mata densa, porém, mantendo a área de cerrado inalterada;

A bacia do Rio São Lamberto, MG demostrou boa conservação do solo devido ao atual uso, apresentando $91,2 \%$ de suas áreas com pequena predisposição aos processos erosivos.

Apesar de constatada pequena predisposição à erosão laminar, a realização de práticas de manejo e conservação do solo e recomposição da vegetação se fazem necessárias para que não haja aumento dos processos erosivos e áreas de solo exposto.

\section{Referências}

ANTUNES, F.Z. Caracterização climática do estado de Minas Gerais: climatologia agrícola. Informe Agropecuário, v.12, p.9-13, 1986.

ARAÚJO, L.E. et al. Bacias Hidrográficas e Impactos Ambientais. In: Qualitas Revista Eletrônica. UEPB, v. 8, n. 1, 2009. 18 p.

BRASIL. Ministério do Meio Ambiente. Panorama da Biodiversidade Global 3. Brasília, 2010. Disponível em: https://doi.org/10.1007/s00740-010-0229-z. Acesso em: 16/04/2018.

BERTONI, J; LOMBARDI NETO, F. Conservação do Solo. 7. ed. São Paulo: Ícone, 2010. 355 p.

COUTINHO, A. C.; MIRANDA, E. E.; MIRANDA, J. R. Utilização de técnicas desegmentação e classificação de imagens LANDSAT-TM para o Mapeamento do Uso das Terras na Região de Campinas, SP. Curitiba - PR, 1997. Disponível em:<http://ainfo.cnptia.embrapa.br/digital/bitstream/item/108807/1/1345.pdf>. Acesso em: 02/09/ 2015.

F.A.O. 1967. La erosión del suelo por el água. Algunas medidas para combatirla en las tierras de cultivo. Cuadernos de fomento agropecuário da Org. de Las Naciones Unidas-FAO Roma, n. 81, 207 p.

FOSTER, G.R.; MCCOOL, D.K.; RENATO, K.G.; MOLDENHAUER, W.C. Conservation of the Universal Soil Loss Equation the SI metric units. Journal of Soil and Water Conservation, Baltimore, v.36, p.355-359, 1981.

IBGE - EMBRAPA - Mapa de Solos do Brasil. Rio de Janeiro: IBGE, 2001 - Escala 1:5.000.000. Disponível em: https://www.ibge.gov.br/geociencias/informacoes-ambientais/pedologia/15829-solos.html?=\&t $=0$-que-e. Acesso em 17/05/2018

MAGALHÃES, I. A.; NERY, C. V. M, ZANETTI, S. S., PENA, F. E. D. R., CECÍLIO, R. A; SANTOS, A. R. D. Uso de geotecnologias para estimativa de perda solo e identificação das áreas susceptíveis a erosão laminar na bacia hidrográfica do rio Vieira, município de Montes Claros, MG. Cadernos de Geociências, v. 9, n. 2, p. 7484, 2012. Disponível em: http://www.mundogeomatica.com.br/Publicacoes/Artigo37.pdf. Acesso em: 08/10/2015. 
MANNIGEL, A. R.; CARVALHO M. D. P.; MORETI, D.; MEDEIROS, L. R. Fator erodibilidade e tolerância de perda dos solos do Estado de São Paulo. Revista Acta Scientiarum, v.24, n.5, p.1335-1340, 2002. Disponível em: http://eduem.uem.br/ojs/index.php/ActaSciAgron/article/view/2374/1787. Acesso em: 05/10/2015.

MINOTI, R. T. Abordagens qualitativa e quantitativa das micro-bacias hidrográficas e áreas alagáveis de um compartimento do médio Mogi-Superior/SP. 2006, 231 f. Tese (Doutorado em Ciências da Engenharia Ambiental) - Escola de Engenharia de São Carlos, 2006. Disponível em: http://www.teses.usp.br/teses/disponiveis/18/18139/tde-23012007-155705/pt-br.php. Acesso em: 29/09/2015.

MOREIRA, M. C.; PRUSKI, F. F.; OLIVEIRA, T. E. C.; PINTO, F. A. C.; SILVA, D. D. NetErosividade MG: Erosividade da chuva em Minas Gerais. Revista Brasileira de Ciência do Solo, v.32, p.1349-1353, 2008.

NASA. Landsat Data Continuity Mission: Continuously Observing Your World. 2013. Disponível em:http://ldcm.gsfc.nasa.gov/mission_details.htm. Acesso em: 04/04/2015.

PAES, F. S., DUPAS, F. A., SILVA, F. G. B. PEREIRA, J. C. D. Espacialização da perda de solo nas bacias hidrográficas que compõem o município de Santa Rita do Sapucaí (MG).Geociências (UNESP. Impresso), v. 29, p. 537-549, 2010. Disponível em: http://ppegeo.igc.usp.br/scielo.php?pid=S010190822010000400012\&script=sci_arttext. Acesso em: 04/10/2015.

PAIVA, E.M.C.D. Métodos de estimativa da produção de sedimentos em pequenas bacias hidrográficas. In: PAIVA, J.B.D.; PAIVA E.L.C.D. (Orgs). Hidrologia Aplicada a Gestão de Pequenas Bacias Hidrográficas. Porto Alegre: UFMS ABRH, p. 283-294, 2001.

PEREIRA, E. A.; SOUSA; A. P.; CAMPOS, S. Mapeamento do uso do solo nas subbacias dos córregos São José e Água do Ventura, Bauru (SP). Revista Irriga. Botucatu-SP: v.7, n.3 p. 191-200, 2002.

REATTO, A.; CORREIA, J.R.; SPERA, S.T.; CHAGAS, C.S.; MARTINS, E.S.; ANDAHUR, J.P.; Godoy, M.J.S. \& Assad, M.L.C.L. Levantamento semi - detalhado dos solos da bacia do rioJardim - DF, escala 1:50.000.

Planaltina: Embrapa Cerrados, 2000.

REDIVO, A.L., FARINASSO, M., RAMOS, V.M., GUIMARÃES, R.F., DE CARVALHO JÚNIOR, O.A., Análise multitemporal do rio São Francisco, no trecho entre os municípios de São Romão e São Francisco no estado de Minas Gerais. GeoUerj, p.1223-1238, 2003.

SANTOS, G. G.; GRIEBELER, N. P.; OLIVEIRA, L. F. C. Intense rainfalls related to water erosion. Revista Brasileira de Engenharia Agrícola e Ambiental, Campina Grande-PB: v.14, n.2, p.115-123, 2010.

SANTOS, H. G.; JACOMINE, P. K. T.; ANJOS, L. H. C. ;OLIVEIRA, V. A. de; LUMBRERAS, J. F.; COELHO, M. R.;ALMEIDA, J. A. ;ARAUJO FILHO, J. C. de; OLIVEIRA, J. B. de; CUNHA, T. J. F. Sistema brasileiro de classificação de solos. Brasília, Serviço de Produção de Informação, 5. ed. Brasilia, DF: EMBRAPA-SPI, 2018. $356 \mathrm{p}$.

SILVA, V. C. Estimativa da Erosão Atual da Bacia do rio Paracatu (MG / GO /DF). Pesquisa Agropecuária Tropical. n.34, v. 3, 147-159, 2004.

SILVA, L. C. N; LUCHIARI, A. Estimativa de Perda de Solos por Erosão Laminar na Bacia Hidrográfica do Córrego Baguaçu-SP. Revista do Departamento de Geografia, 32, 15-28, 2016. https://doi.org/10.11606/rdg.v2i0.114308

SOUSA, F. R. C; PAULA, D. P. Análise de Perda de Solo por Erosão na Bacia Hidrográfica do Rio Coreaú (Ceará-Brasil). Revista Brasileira de Geomorfologia, v.20, n.3, 2019. http://dx.doi.org/10.20502/rbg.v20i3.1393

STEIN, D.P.; DONZELLI, P.L.;GIMENEZA, A.F.; PONÇANO, W.L.; LOMBARDI NETO, F. Potencial de erosão laminar, natural e antrópico, na Bacia do eixeParanapanema. In:Simpósio Nacional de Controle de Erosão. Marília, São Paulo: Anais, ABGE/DAEE, p. 105135, 1987. 


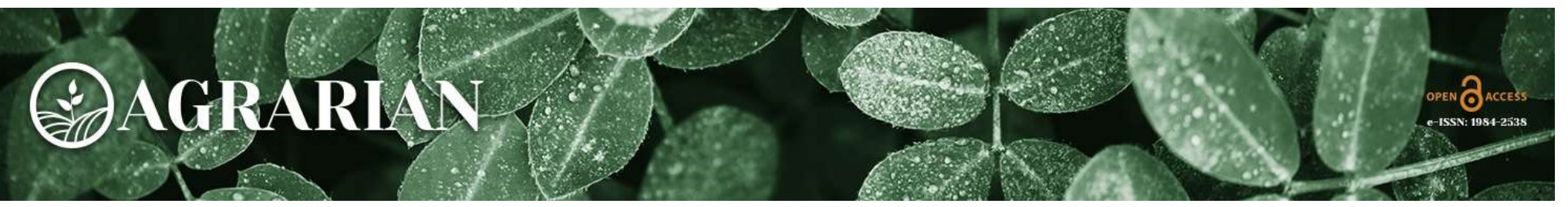

TOMAZONI, J.C.; GUIMARÃES, E. A sistematização dos fatores da EUPS em SIG para quantificação da erosão laminar na bacia do rio Jirau. Revista Brasileira de Cartografia n.57, p.235-244, 2005.

USGS. Landsat Project Description, 2013.2 Disponível em: <http://landsat.usgs.gov/about_project_descriptions.php> Acesso em: 04/04/2015.

VALE JÚNIOR, J. F.; BARROS, L. S.; SOUSA, M. I. L.; UCHÔA, S. C. P. Erodibilidade e suscetibilidade à erosão dos solos de cerrado com plantio de Acacia mangium em Roraima. Revista Agro@mbiente On-line, Boa Vista: v. 3, n. 1, p. 1-8, 2009.

VILLELA, S. M.; MATTOS, A. Hidrologia Aplicada. São Paulo: McGraw-Hill, 1975, 245 p.

WISCHMEIER, W.H., JOHNSON, C. B., CROSS, B.V. A soil erodibility nomograph

for farmland and constrution sites. Jour. Soil Wat. Conserv., v.26, p.189-193, 1971.

WISCHMEIER, W.H.; SMITH, D.D. Predicting rainfall erosion losses - A guide to conservation planning. Agriculture Handbook, Washington: USDA AH-5375, 1978. 58p. 